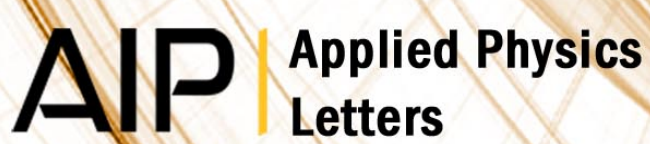

\section{Low dielectric constant Parylene-F-like films for intermetal dielectric applications}

Bengi Hanyaloglu, Atilla Aydinli, Michael Oye, and Eray S. Aydi

Citation: Appl. Phys. Lett. 74, 606 (1999); doi: 10.1063/1.123160

View online: http://dx.doi.org/10.1063/1.123160

View Table of Contents: http://apl.aip.org/resource/1/APPLAB/v74/i4

Published by the American Institute of Physics.

\section{Additional information on Appl. Phys. Lett.}

Journal Homepage: http://apl.aip.org/

Journal Information: http://apl.aip.org/about/about_the_journal

Top downloads: http://apl.aip.org/features/most_downloaded

Information for Authors: http://apl.aip.org/authors

\section{ADVERTISEMENT}

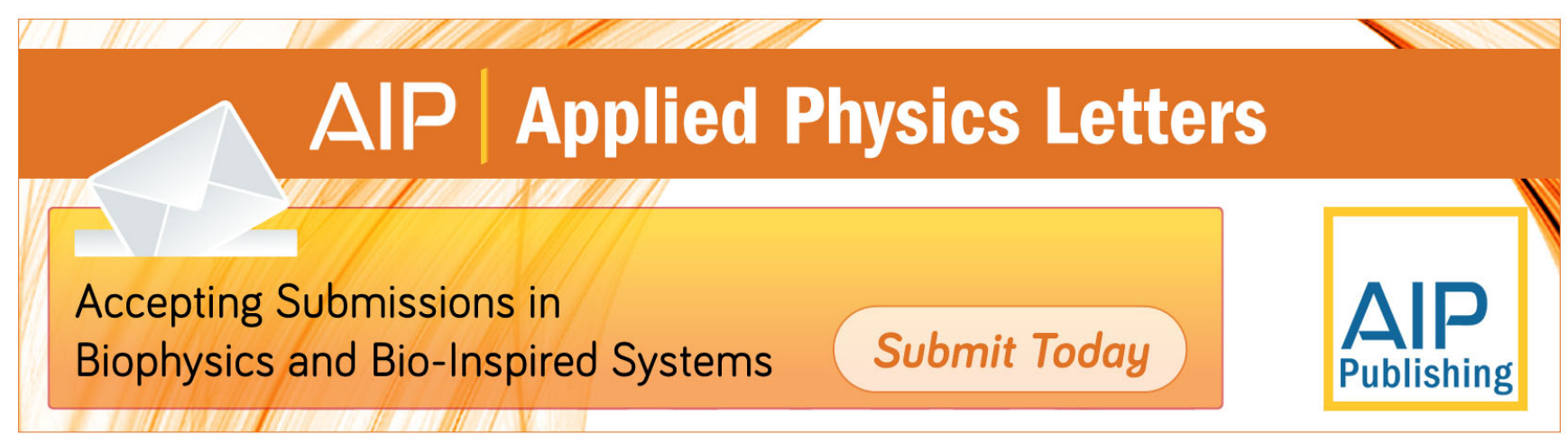




\title{
Low dielectric constant Parylene-F-like films for intermetal dielectric applications
}

\author{
Bengi Hanyaloglu \\ Department of Chemical Engineering, University of California Santa Barbara, Santa Barbara, \\ California 93106 \\ Atilla Aydinli \\ Physics Department, Bilkent University, Ankara, Turkey 06533 \\ Michael Oye and Eray S. Aydi ${ }^{\mathrm{a})}$ \\ Department of Chemical Engineering, University of California Santa Barbara, Santa Barbara, \\ California 93106
}

(Received 28 August 1998; accepted for publication 20 November 1998)

\begin{abstract}
We report on the dielectric properties and thermal stability of thin polymer films that are suitable candidates for replacing silicon dioxide as the intermetal dielectric material in integrated circuits. Parylene-F-like films, $\left(-\mathrm{CF}_{2}-\mathrm{C}_{6} \mathrm{H}_{4}-\mathrm{CF}_{2}-\right)_{n}$, were produced by plasma deposition from a mixture of $\mathrm{Ar}$ and 1,4-bis(trifluoromethyl)benzene $\left(\mathrm{CF}_{3}-\mathrm{C}_{6} \mathrm{H}_{4}-\mathrm{CF}_{3}\right)$ discharges and characterized using infrared absorption spectroscopy, spectroscopic ellipsometry, and capacitance measurements. The dielectric constant and the magnitude of the electronic and ionic contributions to the dielectric constant were determined through capacitance measurements and Kramers-Kronig analysis of the infrared absorption data. The film's dielectric constant ranges between 2 and 2.6 depending on the deposition conditions and the largest contribution to the dielectric constant is electronic. The films deposited at $300{ }^{\circ} \mathrm{C}$ are stable above $400{ }^{\circ} \mathrm{C}$ and further optimization could push this limit to as high as $500{ }^{\circ} \mathrm{C}$. (C) 1999 American Institute of Physics. [S0003-6951(99)04304-1]
\end{abstract}

At the turn of the century, typical logic devices are projected to use several kilometers of metal interconnects and as many as eight to nine intermetal layers. Silicon dioxide, the present intermetal dielectric (IMD), needs to be replaced by a material with lower dielectric constant to decrease the RC time constant of the interconnects and the cross talk between the metal lines. Aeorogels, ${ }^{1}$ amorphous fluorinated carbon, ${ }^{2,3}$ and Parylene ${ }^{4-7}$ films are some of the possible candidates for the the IMD layers to be used in the next generation of logic devices.

Paraxylylene thin films, generically referred to as Parylene, are a class of polymeric thin films with low dielectric constant, high thermal stability, and resistance to moisture absorption. ${ }^{5,6,8}$ Specifically, Parylene films have dielectric constants of 2.35-2.95 at $1 \mathrm{MHz}$ and are stable at temperatures up to $400-500{ }^{\circ} \mathrm{C} .{ }^{6}$ In particular, Parylene-F type films $\left(-\mathrm{CF}_{2}-\mathrm{C}_{6} \mathrm{H}_{4}-\mathrm{CF}_{2}-\right)_{n}$ have a reported decomposition temperature of $530{ }^{\circ} \mathrm{C}$ and a low frequency dielectric constant that ranges between 2.35 to 2.75 , which depends on the deposition conditions and post deposition treatments. ${ }^{4-8}$

At present, there are two methods for depositing Parylene-F films. In Gorham's method, the solid dimer $\left(-\mathrm{CF}_{2}-\mathrm{C}_{6} \mathrm{H}_{4}-\mathrm{CF}_{2}-\right)_{2}$ is sublimed and then cracked at $720-$ $730{ }^{\circ} \mathrm{C}$ to produce the monomer which is polymerized on the substrate to obtain Parylene-F films. ${ }^{8,9}$ In a second, more recent, method $\mathrm{CF}_{2} \mathrm{Br}-\mathrm{C}_{6} \mathrm{H}_{4}-\mathrm{CF}_{2} \mathrm{Br}$ precursor is passed over a bed of $\mathrm{Zn}$ catalyst particles maintained at $350{ }^{\circ} \mathrm{C}$ to strip the $\mathrm{Br}$ atoms forming the reactive $\left(-\mathrm{CF}_{2}-\mathrm{C}_{6} \mathrm{H}_{4}-\mathrm{CF}_{2}-\right)$ monomer which is subsequently polymerized on the sub-

${ }^{\text {a)} E l e c t r o n i c ~ m a i l: ~ a y d i l @ e n g i n e e r i n g . u c s b . e d u ~}$ strate surface. ${ }^{6}$ A simpler process that is compatible with current dielectric deposition reactors and processes would be preferred. Plasma assisted deposition methods are practical and are widely used to deposit the current $\mathrm{SiO}_{2}$ intermetal dielectric films.

While plasma deposition of amorphous fluorinated carbon films from fluorocarbon gases, such as $\mathrm{CF}_{4}$ and $\mathrm{C}_{2} \mathrm{~F}_{6}$, have been reported, problems with their thermal stability and adhesion continue to plague their use as IMD material. ${ }^{2,3,10,11}$ For example, films deposited from $\mathrm{C}_{2} \mathrm{~F}_{6}$ plasma are stable only up to $300{ }^{\circ} \mathrm{C}$ and lose $50 \%$ of their thickness upon heating to $400{ }^{\circ} \mathrm{C} .{ }^{3}$ Incorporation of aromatic rings into the film, as in Parylene, would increase the stability of carbon films without sacrificing from the low dielectric constant. However, to our knowledge, plasma deposition of Parylene films has not yet been attempted. In this letter, we report the first successful plasma enhanced chemical vapor deposition (PECVD) of a Parylene-F-like polymer films from 1,4bis(trifluoromethyl)benzene precursor. We demonstrate that low dielectric constant films for IMD with properties and structure similar to Parylene-F can be deposited from a plasma.

The films were deposited in the helical resonator plasma reactor shown in Fig. 1. The liquid precursor, 1,4bis(trifluoromethyl)benzene (BTFMB), is placed in a glass bulb maintained at $0{ }^{\circ} \mathrm{C}$. BTFMB vapor is transported into the reactor by Ar carrier gas and the Ar flow rate is controlled by a mass flow controller. The carrier gas and the precursor vapor are fed into the reactor through a gas injection ring that surrounds the resistively heated substrate. The balance Ar gas, metered by a mass flow controller, enters the reactor from a gas inlet at the top of the reactor. The pres- 


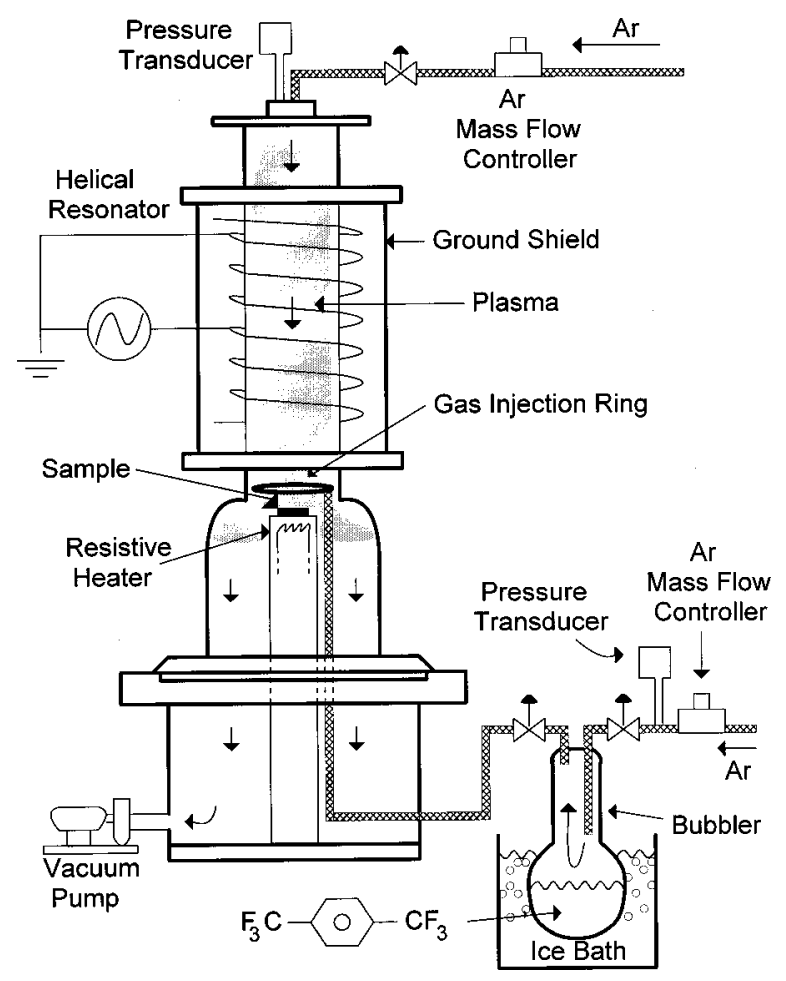

FIG. 1. Schematic of the PECVD reactor used for depositing Parylene-F like films.

sure, power, Ar, and BTFMB flow rates were maintained at $250 \mathrm{mTorr}, 80 \mathrm{~W}, 71$, and $9 \mathrm{sccm}$, respectively.

Films were deposited on $\mathrm{Si}$ (001) substrates and on Ge (001) crystals cut into $5 \times 1 \mathrm{~cm}^{2}$ pieces with $45^{\circ}$ bevels on each of the short sides for attenuated total reflection Fourier transform infrared (ATR-FTIR) spectroscopy. ${ }^{12-15}$ Thickness and index of refraction of the films were determined using spectroscopic ellipsometry. Metal-insulator-metal capacitors were produced on Si substrates coated with a $300 \AA$ Ti adhesion layer followed by a $5000 \AA$ A thick Au film. After depositing $1 \mu \mathrm{m}$ thick polymer film, capacitors were formed by evaporating $0.1 \mathrm{~mm}^{2}$ and $3800 \AA$ thick Al dots. Dielectric constants at $1 \mathrm{MHz}$ were determined from the measured capacitances.

Films were deposited at substrate temperatures ranging from 25 to $30{ }^{\circ} \mathrm{C}$. The deposition rate, determined by dividing the total film thickness by the deposition time, decreases from $3200 \AA / \mathrm{min}$ at $25^{\circ} \mathrm{C}$ to $800 \AA / \mathrm{min}$ at $100{ }^{\circ} \mathrm{C}$ and remains constant thereafter. Films deposited below $100^{\circ} \mathrm{C}$ are very soft and probably unsuitable for IMD applications. Figure 2 shows the dielectric constant and the refractive index of the deposited films as a function of the substrate temperature. The square of the refractive index, which represents the electronic contribution to the dielectric constant, is also plotted on the same figure. The films' dielectric constant increases from 2.0 to 2.6 with increasing deposition temperature and is in the same range as Parylene-F films and as low as the best plasma deposited films from straight chain fluorocarbon gases. $2,3,10,11$

We have also calculated the dielectric constant from the spectroscopic ellipsometry and infrared absorption data using Kramers-Kronig transformation and the procedure described by Han and Aydil ${ }^{14}$ The dielectric constant calculated using this method was within $10 \%$ of the values

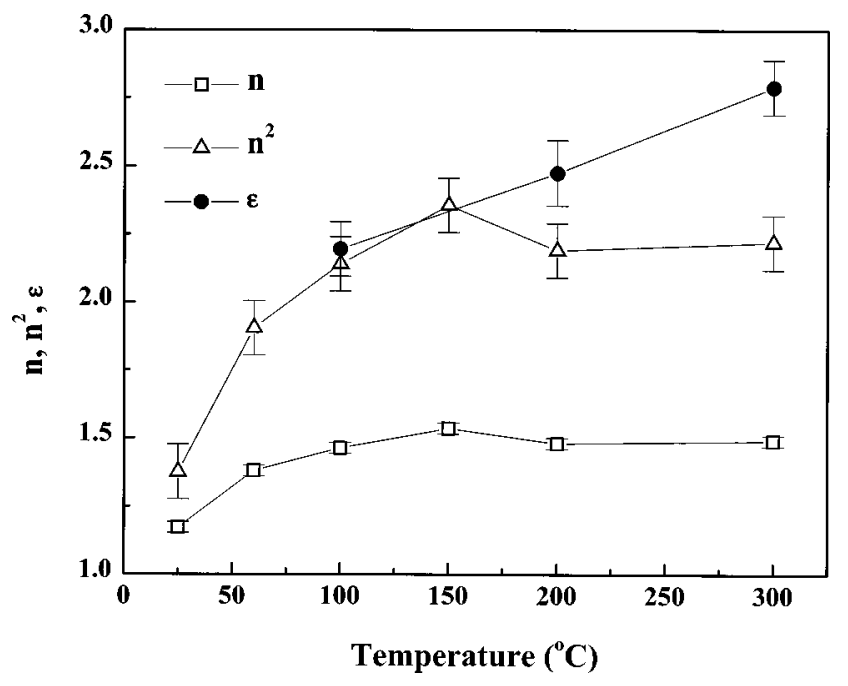

FIG. 2. Low frequency $(1 \mathrm{MHz})$ dielectric constant, $\epsilon$, the refractive index (at $633 \mathrm{~nm}$ ), $n$, and the square of the refractive index, $n^{2}$, for plasma deposited parylene films as a function of the substrate temperature.

determined from the capacitance measurements. The Kramers-Kronig analysis also revealed that the largest contribution to the dielectric constant is electronic in these films. This finding is illustrated in Fig. 2 by plotting the square of the refractive index, which is almost equal to the $1 \mathrm{MHz}$ dielectric constant.

Figure 3(a) shows the infrared spectrum of the film deposited at $200^{\circ} \mathrm{C}$ and Fig. 3(b) is the infrared spectrum of the BTFMB liquid precursor. Except for broadening of the absorptions and an additional strong band at $1280 \mathrm{~cm}^{-1}$ in the solid film, the two spectra appear very similar, indicating that the chemical structure of the molecules that make up the polymeric film is very similar to the liquid precursor molecules. Detailed assignments of the infrared absorption peaks and discussion of the spectral features will be presented in a future publication. For the purposes of this letter, we concentrate on those absorptions that give insight into the structure of the films and present evidence that the films closely resemble Parylene-F. In Fig. 3(b), the absorptions at 1129, 1165 , and $1322 \mathrm{~cm}^{-1}$ in the liquid precursor spectra are the two asymmetric and symmetric stretching $\mathrm{C}-\mathrm{F}$ vibrations of

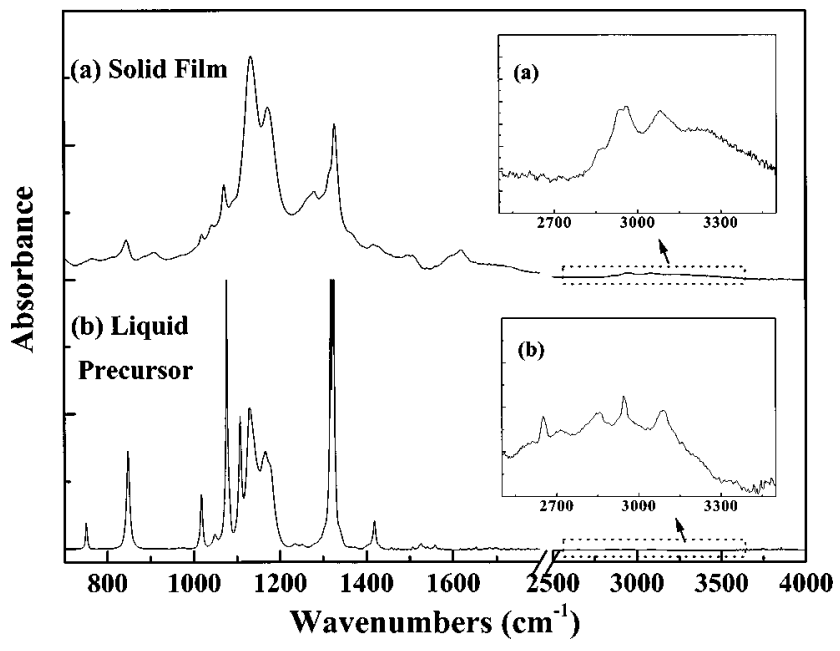

FIG. 3. Infrared spectra of (a) the Parylene-F like film deposited at $200{ }^{\circ} \mathrm{C}$ and (b) the liquid precursor, 1,4-bis(trifluoromethyl)benzene. 
the $\mathrm{CF}_{3}$ bonded to an aromatic ring, respectively. ${ }^{16}$ The spectrum of the deposited film also displays absorptions at 1130, 1170 , and $1326 \mathrm{~cm}^{-1}$. The asymmetric stretching frequency is split into two peaks, in both the liquid precursor and in the film due to the influence of the benzene ring; this splitting is a strong indicator of the presence of aromatic rings in the deposited films. ${ }^{16}$ Similarity of these absorptions to those in the liquid precursor also indicates that majority of the benzene rings remains intact upon deposition and dissociation of the aromatic rings in the discharge is minimal. Additional evidence for presence of aromatic rings in the deposited film comes from the $\mathrm{C}-\mathrm{H}$ stretching absorption frequency region. The absorption peak at $3090 \mathrm{~cm}^{-1}$ is the $\mathrm{C}-\mathrm{H}$ stretching mode of the $\mathrm{H}$ atom bonded to a benzene ring. Same stretching absorptions are observed both in the liquid and the deposited films indicating that the $\mathrm{H}$ atoms in the film are attached to the benzene ring.

The absorption band at $1280 \mathrm{~cm}^{-1}$ is absent in the liquid [Fig. 3(b)] but is present in the film [Fig. 3(a)]. This absorption is assigned to $\mathrm{CF}_{2}$ stretching modes. ${ }^{6}$ Presence of this band is taken as evidence that the benzene rings of the liquid precursor have been connected together through the $\mathrm{CF}_{3}$ substitution sites to form the Parylene- $\mathrm{F}$ polymer, $\left(-\mathrm{CF}_{2}-\mathrm{C}_{6} \mathrm{H}_{4}-\mathrm{CF}_{2}-\right)_{n}$. Furthermore, the $\mathrm{C}-\mathrm{H}$ out-of-plane bending mode is observed as a single peak at $843 \mathrm{~cm}^{-1}$, characteristic of $\mathrm{H}$ bonded to paradisubstituted aromatic rings. Thus, all the evidence from the infrared spectra suggests that the deposited films have a chemical composition and structure similar to that of Parylene-F.

In formulating the idea to deposit Parylene films by PECVD, we had anticipated that the reactive $\mathrm{CF}_{3}-\mathrm{C}_{6} \mathrm{H}_{4}-\mathrm{CF}_{2}-$ radical could be formed by electron impact dissociation of the BTFMB molecules in the gas phase via the reaction

$$
\mathrm{CF}_{3}-\mathrm{C}_{6} \mathrm{H}_{4}-\mathrm{CF}_{3}+e \rightarrow \mathrm{CF}_{3}-\mathrm{C}_{6} \mathrm{H}_{4}-\mathrm{CF}_{2}+\mathrm{F}+e^{-}
$$

and polymerized to yield Parylene-F like films. We presumed that if the electron density and energy is low enough, the monomer radical could be formed without breaking the aromatic rings. Indeed, the infrared, the capacitance measurements, and the ellipsometry data all suggest that the aromatic rings are intact and the plasma deposited films have structure and properties very close to those of Parylene-F films.

One of the requirements for the intermetal dielectrics is high thermal stability. We have studied the thermal behavior of our films by annealing them for $15 \mathrm{~min}$ in flowing $\mathrm{N}_{2}$ gas at atmospheric pressure and subsequently measuring the changes in their thickness, refractive index, and infrared spectra. Figure 4 shows the change in film thickness and refractive index of a film deposited at $300^{\circ} \mathrm{C}$ as a function of the annealing temperature. The change in the film thickness is often used as an indicator of the film's stability upon heating. Clearly, the plasma deposited Parylene-F-like films are stable above $400{ }^{\circ} \mathrm{C}$ and comparable to Parylene films deposited by other methods. Above $400^{\circ} \mathrm{C}$, the film thickness

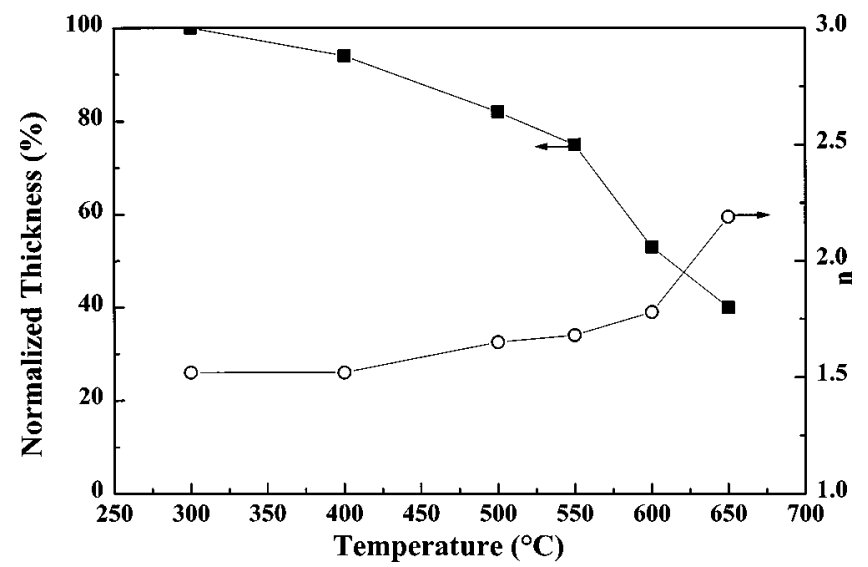

FIG. 4. Changes in the thickness of the Parylene films deposited at $300{ }^{\circ} \mathrm{C}$ as a function of annealing temperature. The thickness is normalized with the thickness of the as deposited film.

starts to decrease while the refractive index increases with annealing temperature. However, the infrared spectra of the films annealed below $500{ }^{\circ} \mathrm{C}$ did not change drastically indicating that the change in film thickness may be due to compaction of the polymer chains during annealing and not due to dissociation or chemical changes in the film. It should be noted that the deposition process described here has not yet been optimized and further process optimization to deposit more compact films can increase the temperature stability limit to $530^{\circ} \mathrm{C}$, the expected decomposition limit for Parylene-F films.

This work was funded by the National Science Foundation Young Investigator Program (Award No. ECS 9457758) and the State of California SMART program. One of us (A. A.) is grateful to a Fullbright Scholarship that made this collaborative work possible. Insightful discussions with S. M. Han and technical help from E. Edelberg are also acknowledged.

${ }^{1}$ C. C. Cho, D. M. Smith, and J. Anderson, Mater. Chem. Phys. 42, 91 (1995).

${ }^{2}$ K. Endo and T. Tatsumi, J. Appl. Phys. 78, 1370 (1995).

${ }^{3}$ K. Endo and T. Tatsumi, Appl. Phys. Lett. 68, 2864 (1996).

${ }^{4}$ S. Dabral, X. Zhang, X. M. Wu, G. R. Yang, L. You, C. I. Lang, K. Hwang, G. Cuan, C. Chiang, H. Bakhru, R. Olson, J. A. Moore, T. M. Lu, and J. F. McDonald, J. Vac. Sci. Technol. B 11, 1825 (1993).

${ }^{5}$ P. K. Wu, G. R. Yang, L. You, D. Mathur, A. Cocoziello, C. I. Lang, J. A. Moore, and T. M. Lu, J. Electron. Mater. 26, 949 (1997).

${ }^{6}$ L. You, G. R. Yang, C. I. Lang, J. A. Moore, P. Wu, J. F. McDonald, and T. M. Lu, J. Vac. Sci. Technol. A 11, 3047 (1993).

${ }^{7}$ J. J. Senkevich and S. B. Desu, Appl. Phys. Lett. 72, 258 (1998).

${ }^{8}$ S. W. Chow, W. E. Loeb, and C. E. White, J. Appl. Polym. Sci. 13, 2325 (1969).

${ }^{9}$ W. F. Gorham, J. Appl. Polym. Sci. 4, 3027 (1966).

${ }^{10}$ S. Takeishi, H. Kudo, R. Shinohara, M. Hoshino, S. Fukuyama, J. Yamaguchi, and M. Yamada, J. Electrochem. Soc. 144, 1797 (1997).

${ }^{11}$ K. Endo and T. Tatsumi, Appl. Phys. Lett. 68, 3656 (1996).

${ }^{12}$ E. S. Aydil and R. A. Gottscho, Solid State Technol. 40, 181 (1997).

${ }^{13}$ Y. J. Chabal, Surf. Sci. Rep. 8, 211 (1988).

${ }^{14}$ S. M. Han and E. S. Aydil, J. Appl. Phys. 83, 2172 (1998).

${ }^{15}$ N. J. Harrick, Internal Reflection Spectroscopy (Wiley, New York, 1967).

${ }^{16}$ R. R. Randle and D. H. Whiffen, J. Chem. Soc. 47, 1311 (1955). 